\title{
Design of a 450-passenger blended wing body aircraft for active control investigations
}

\author{
B Mohr ${ }^{1 *}$, D Paulus ${ }^{1}$, H Baier ${ }^{2}$, and M Hornung ${ }^{1}$ \\ ${ }^{1}$ Institute of Aircraft Design, Technische Universität München, München, Germany \\ ${ }^{2}$ Institute of Lightweight Structures, Technische Universität München, München, Germany
}

The manuscript was received on 16 May 2011 and was accepted after revision for publication on 19 September 2011.

DOI: $10.1177 / 0954410011426031$

\begin{abstract}
ACFA 2020 (active control for flexible aircraft) is a collaborative research project funded by the European Commission under the seventh research framework programme. The project deals with innovative active control concepts for 2020 aircraft configurations like the blended wing body (BWB) aircraft. The main objectives of ACFA are the design of a new ultra efficient 450 passenger BWB type aircraft as well as the provision of robust adaptive multichannel control architectures for such aircraft. The objective of the newly designed controllers is an ambitious improvement of ride comfort and handling qualities, as well as load reduction on BWB type aircraft. Based on the attained load reduction, the structure of the 450-passenger aircraft can be resized with the goal of an ambitious weight saving for further improvement of fuel efficiency. Active control requirements influence the design process of control surfaces and overall aircraft design, respectively. Hence, the conventional aircraft design process had to be adapted to the new requirements. The aircraft design framework described in this article has proven its efficiency in the development of the ACFA BWB aircraft. Within a time period of 1 year, an airframe has been developed under the constraints of multiple domain requirements. This article presents the process and the results of the design activities of the BWB aircraft, which form the basis for a detailed concept analysis as well as the investigation of multiple-input multipleoutput control architectures.
\end{abstract}

Keywords: blended wing body, BWB, active control, aircraft design, ACFA 2020

\section{PROJECT CONCEPT AND OBJECTIVES}

The Advisory Council for Aeronautics Research in Europe (ACARE) proposed the Strategic Research Agenda (SRA) in November 2001 and an updated version in March 2008. The SRA is the road map for realizing the 'ACARE vision 2020' [1, 2], which aims at:

(a) 50 per cent reduced fuel consumption and related carbon dioxide $\left(\mathrm{CO}_{2}\right)$ emissions per passengerkilometer;

(b) reduced perceived noise to one half of current average levels;

*Corresponding author: Institute of Aircraft Design, Technische Universität München, Boltzmannstrasse 15, 85748 Garching, München, Germany.

email:mohr@tum.de (c) improvement of handling qualities and ride comfort.

These ambitious goals can only be achieved through major changes in future aircraft configurations. Highly promising concepts with regard to improved fuel efficiency are blended wing body (BWB) aircraft configurations (i.e. tailless aircraft configurations with aerodynamic wing/fuselage blending). Low fuel consumption is mainly achieved by drag reduction, reduced structural weight, and through the significantly lower ratio of wetted area/ reference area for BWB aircraft compared to other configurations. Exterior noise signature can be reduced by a simplified high-lift system (morphing trailing edge) and by integrating the engines over the rear fuselage or in the airframe. Major design issues of such BWB-type aircraft have been recently 
investigated, which represent a solid basis for design considerations of the active control for flexible aircraft (ACFA) BWB [3-6]. The challenge created by the complex active control system for BWB-type aircraft has been identified, but not yet addressed in detail. Therefore, the two main challenges investigated within the ACFA 2020 project are described in the following sections.

\subsection{Pre-design of the ACFA 2020 aircraft configuration}

Since the biggest market share in long haul flights is taken by mid-size aircraft (400-500 passengers), a new ultra-efficient 450 passenger tailless composite aircraft with aerodynamic wing/fuselage blending is devised within the ACFA 2020 project. For minimum exterior noise signature, the engines are mounted over the rear fuselage. The choice for this layout was supported by results of a detailed analysis of shielding engine noise with the airframe structure [5, 7]. Based on the multiple-input multiple-output (MIMO) control strategy results obtained, the structure of the ACFA 2020 aircraft configuration will be resized to demonstrate the potential weight benefit achieved by active control. The contribution to the ACARE emission reduction goals is investigated at the end of the project.

\subsection{Providing solutions for the active control system}

Active control systems for the alleviation of structural vibrations as well as of gust and manoeuvre loads have been investigated for conventional aircraft configurations $[\mathbf{8}, \mathbf{9}]$. Such active control systems are an important means for the reduction of critical loads as well as for the improvement of ride comfort and handling qualities. Load reduction increases aircraft efficiency by reducing structural weight. Thus, it is self-evident to incorporate active structural control into future aircraft configurations. However, BWB type aircraft set completely new challenges with regard to complexity of control algorithms, control design and optimization, as well as control system architecture. Instead of various single-channel or single-input-single-output controllers, a highly coupled multi-channel or MIMO controller is required. Thus, the main objective of ACFA 2020 is to provide robust as well as adaptive MIMO architectures for active control of BWB-type aircraft. The aim of providing solutions for the required active MIMO control on BWB-type aircraft is to get closer to the realization of a highly efficient future aircraft configuration, and also to make BWB-type aircraft even more efficient by reducing structural weight through active control. An additional objective is to make BWB aircraft more passenger friendly by increasing ride comfort with the use of active control.

This article possesses the following structure. After the introduction to the overall project context and its objectives, the design for active control and the inherent challenges are discussed in section 2 . Subsequently, the aerodynamic design and especially the airfoils and control surface calculations are presented in section 3. Section 4 presents structural weight estimations and the comparison to similar designs precedes section 5 on performance, which describes the results of a takeoff (TO) and landing analysis as well as mission performance calculations. Concluding this article, the findings are summarized and an outlook with regard to the ACARE vision and ACFA project is discussed in section 6 .

\section{DESIGN FOR ACTIVE CONTROL}

The ACFA aircraft design activities focus on active control technology (ACT) as a design principle for future aircraft configurations. ACT stands for the use of controller technologies that enable improved flight performance and possible beneficial effects on the overall aircraft design (e.g. direct lift control or flutter control). ACT has become a standard for military aircraft configurations which are highly unstable but is still rare in civil aircraft design. The main reasons for this are the rather complex control systems and the respective certification issues. However, diminishing fuel resources make economic flying more important and ACT is one means to improve aircraft efficiency. The ACT mechanisms for improved payload and range are shown in Fig. 1.

Possible ACT applications are given as follows:

(a) reduction of static longitudinal stability margin;

(b) manoeuvre and gust load alleviation;

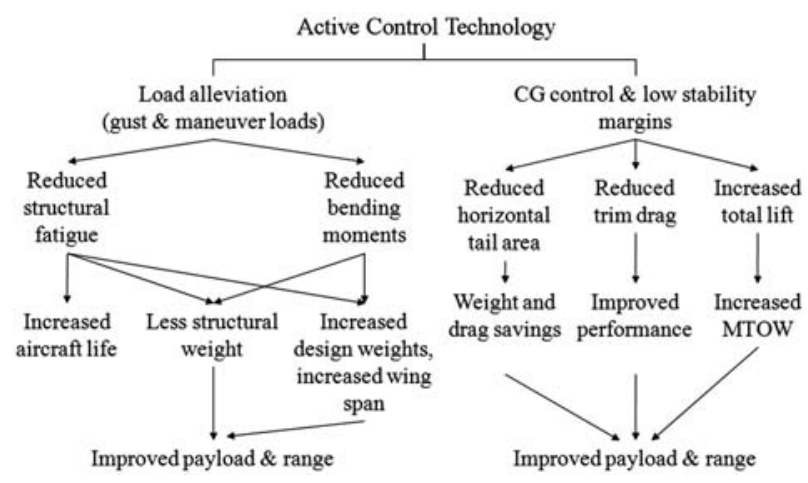

Fig. 1 Contribution of active control to improved payload and range (adapted from [10]) 
(c) adaptive wing;

(d) flutter damping;

(e) direct lift and lateral force control.

By integrating ACT principles, the traditional aircraft design process is changed. The design of control surfaces and the respective controllers is integrated in the iterative overall aircraft configuration process (Fig. 2). In conventional aircraft design, the influence of control surface design on wing and stabilizer dimensions as well as structural layout has not been closely coupled. If ACT principles are integrated more deeply into the overall design process, the possibility to perform interdisciplinary studies has to be provided. Best results are achieved if ACT requirements are included in the design requirements as early as possible [11]. It is obvious that a greater level of interdisciplinary tasks requires a high level of communication and well-defined interfaces between project partners across Europe. The results of the newly defined ACT aircraft design process are presented in the following sections.

\section{AERODYNAMIC ANALYSIS}

\subsection{Airfoils aerodynamics}

BWB configurations require special airfoils that differ from standard profiles in many ways. The profile for the centre section has to provide the space for the cabin and must therefore have ample thickness. The thickness, however, is limited by aerodynamic performance considerations, especially wave drag. The thickness of the profile also influences the length of the centre body, which has an influence on friction drag and rotation clearance at TO. Generally, relatively low lift coefficients are required at the centre body and higher lift coefficients at the outer wing. The aerodynamic model for the identification

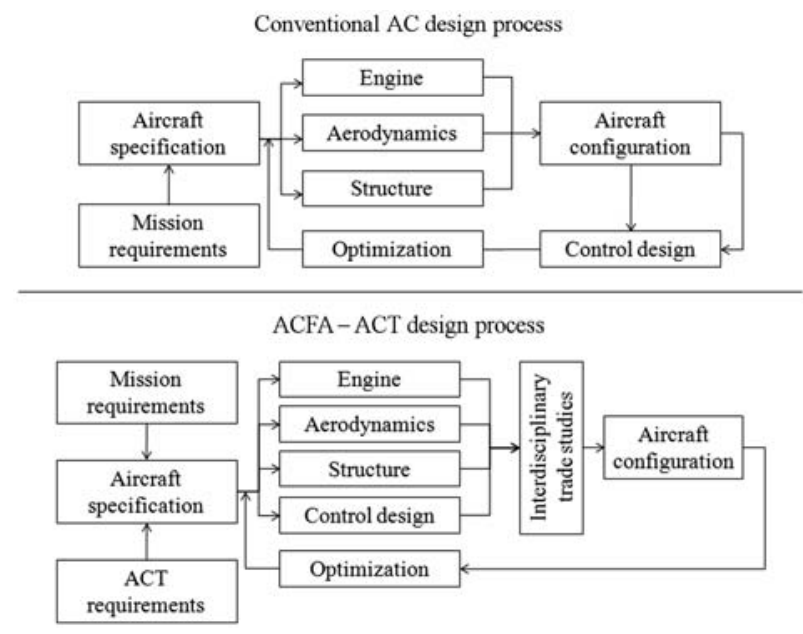

Fig. 2 ACT aircraft design process (adapted from [10]) of the twist distribution of the configuration was established with the linear-vorticity stream function panel method implemented in XFLR5 [12]. The research project multidisciplinary optimization of a BWB investigated several span loading scenarios and concluded that an averaged elliptic/triangular distribution enables the best aerodynamic performance for blended wings measured by the $L / D$ ratio or the total drag at the design cruise condition [13]. Therefore, the twist distribution ACFA BWB was adjusted to the proposed spanwise lift distribution (Fig. 3). For a known chord length, local lift and $C_{\mathrm{L}}$ upon alpha distribution, it is possible to determine local incidence angles at a discrete number of twodimensional (2D) profiles. As the overall geometry is three-dimensional (3D), the calculated twist distribution is not necessarily consistent with the target lift distribution if analysed with the panel code again. With few iterative steps, local twist has been manually refined until the spanwise twist and target lift distribution was sufficiently met with airfoils developed, especially for the ACFA BWB.

Figures 4 and 5 show the final profiles of the centre body and the outer wing as well as respective pressure distribution at incidence angles at the design point. Clearly visible are trailing edge upwards movement in the centre body for trim reasons and the supercritical airfoil at the outer wing for shock-delaying characteristics.

Flight stability was optimized iterating wing sweep for a given lift and a given surface with an evolutionary algorithm. The objective function of the optimization aimed to equally maximize glide ratio and minimize the longitudinal positive moment coefficient $C_{\mathrm{m}}$. Because the induced drag penalty of a positive pitching moment coefficient is much lower at the centre body than at the outer wing, the centre body profile has a positive moment coefficient. At the outer wing, the moment coefficient is slightly negative to enable a stable configuration.

\subsection{Aircraft aerodynamics}

Lift and drag calculations to study the aerodynamics of the BWB at different angles of attacks and flight altitudes were conducted using a combination of several empirical methods. For drag analysis of the ACFA BWB, DATCOM [14] was used to analyse the effects of form and lift-induced drag. To account for the different airfoils used in the centre and outer wing sections, the wing was divided into five panels with corrections being made for Reynolds number and lifting surface geometry at subsonic speeds. Skin friction drag was added as discussed in Schemensky [15]. Drags due to twist or crank influences were taken from Torenbeek 

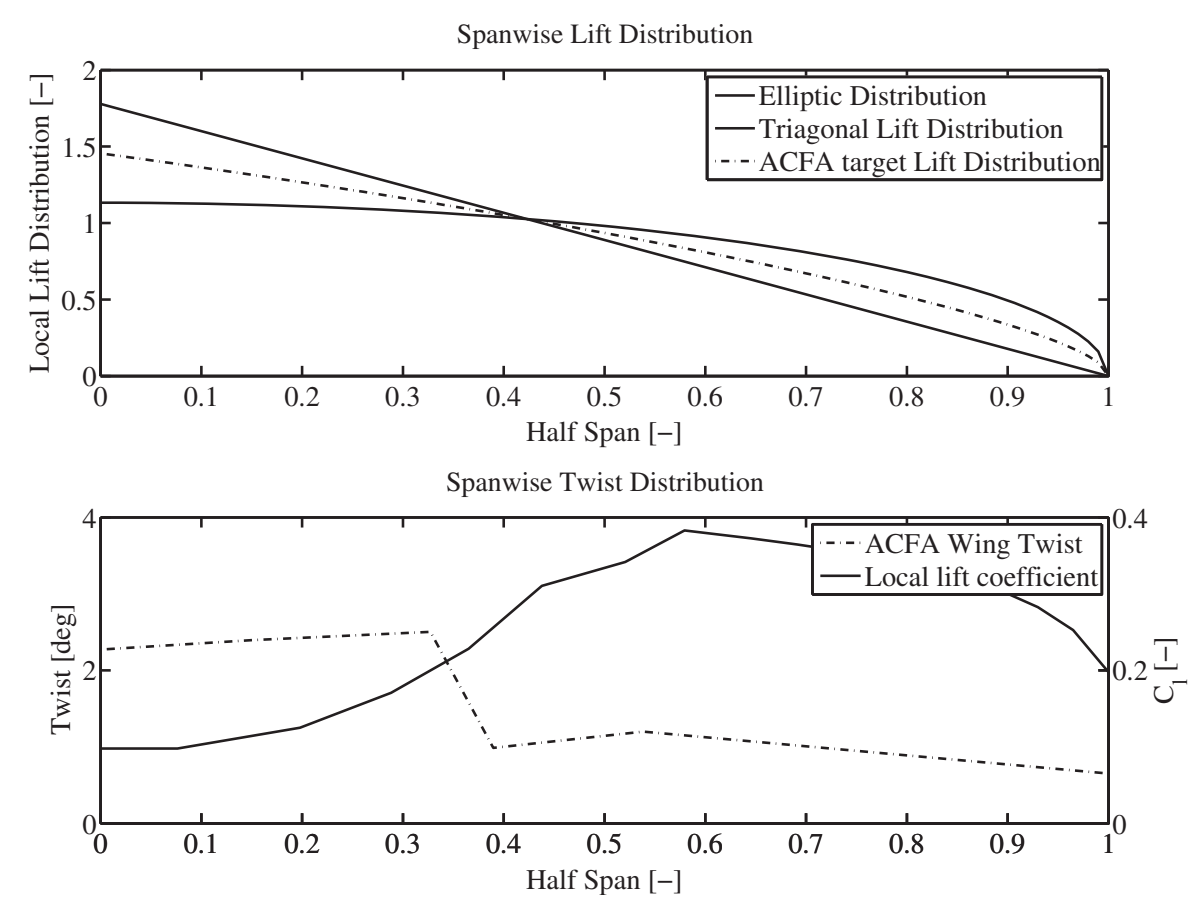

Fig. 3 ACFA wing twist and local lift distribution
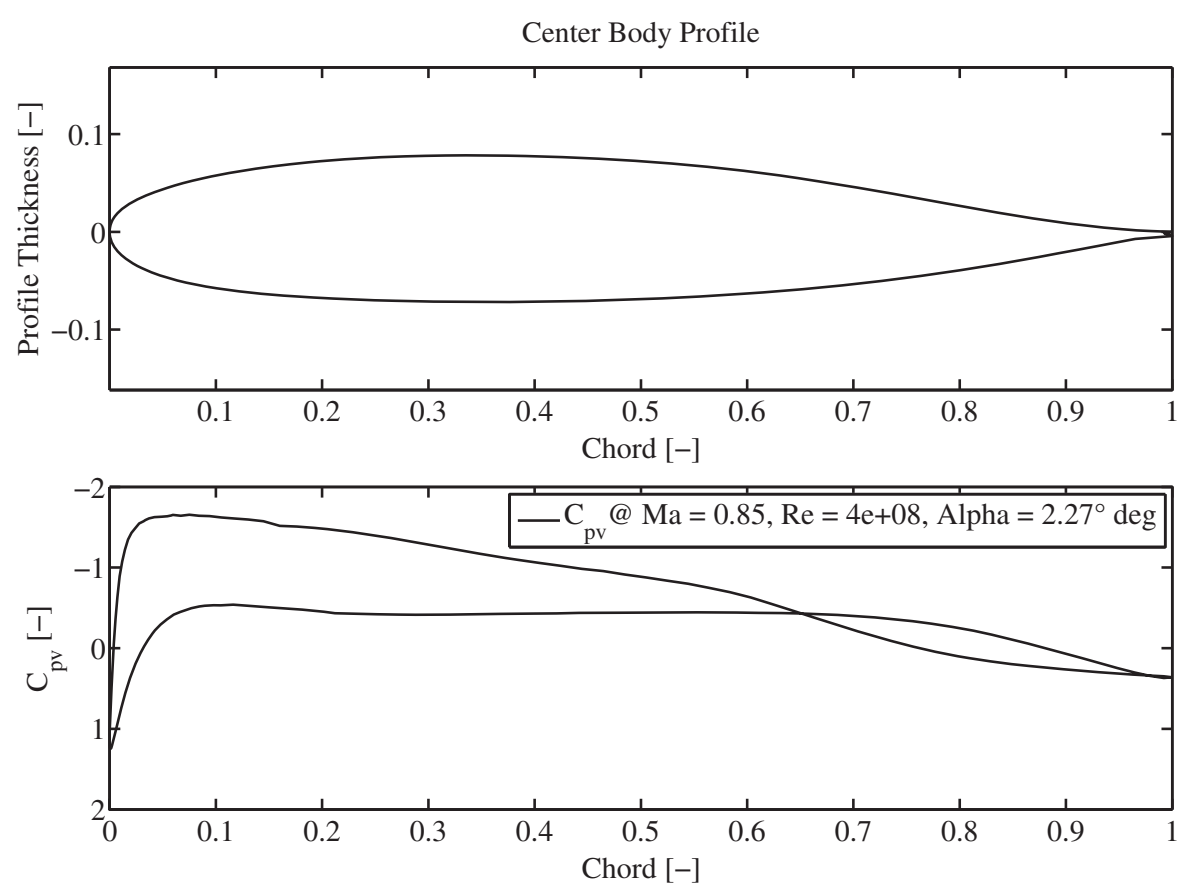

Fig. 4 ACFA BWB centre body profile and $C_{\mathrm{p}}$ distribution

[16]. Interference drag was considered only in that body drag based on its geometry computed with DATCOM. The results were compared to a code that combines viscous $2 \mathrm{D}$ profile calculations based on XFOIL with an enhanced lifting line theory [12] and to the published research results $[\mathbf{1 7 - 1 9}]$. The lowfidelity XFOIL model can efficiently be used for load cases at lower Mach numbers, e.g. approach load case at $M=0.2$. To assess the effectiveness of the methodology over the entire speed regime, a 3D numerical calculation was carried out at project partner Airbus France.

It could be demonstrated that for the level of detail chosen, the results achieved for subsonic speed regimes were consistent among the different available data sources. However, the analytical 

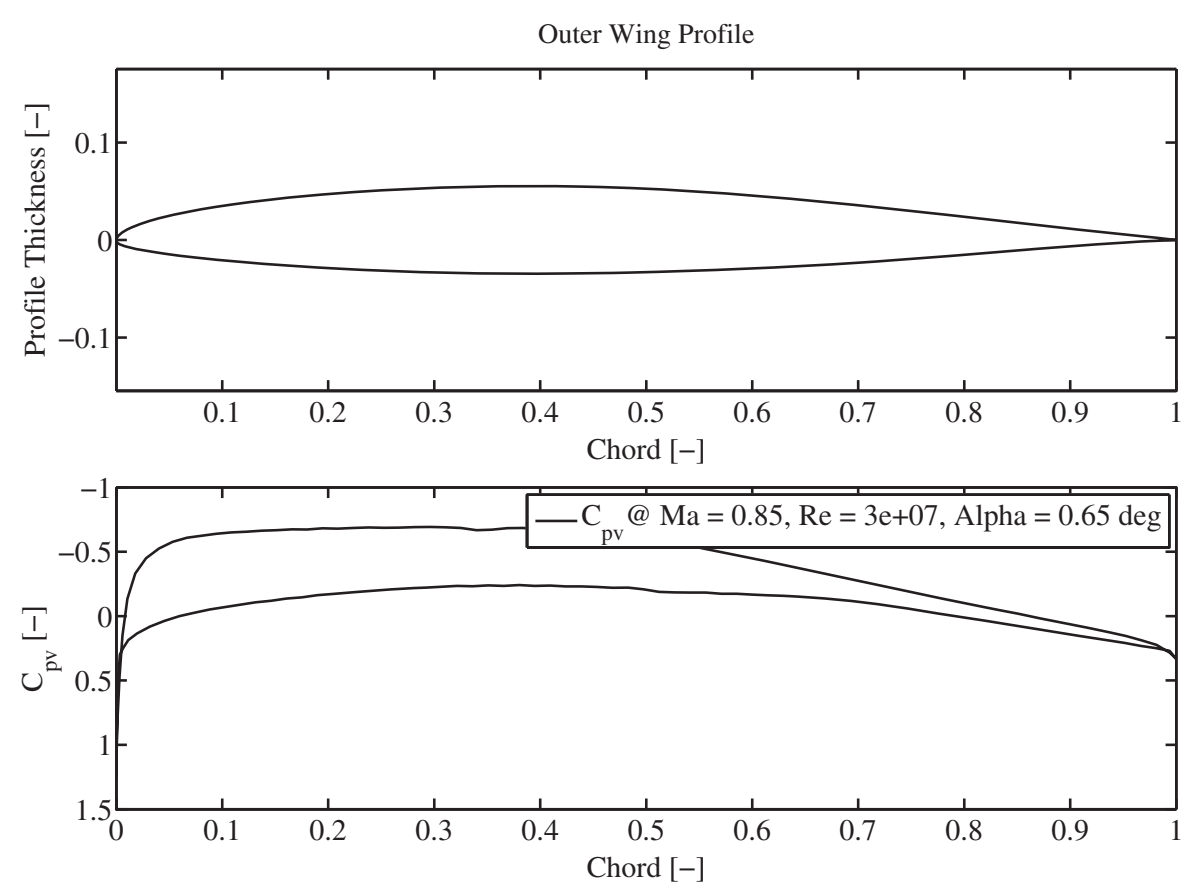

Fig. 5 ACFA BWB wing profile and $C_{\mathrm{p}}$ distribution

computation of transonic wave drag effects proved to be inaccurate for several reasons. Expressions of higher order are usually neglected in analytical formulas, although their influence is significant in the transonic regime. The complexity of the different unconventional cross-sections is only inaccurately reflected with conventional methods which often ignore wave-drag-due-to-lift effects.

Analytical methods such as the Lock formula described and adapted by Malone and Mason [20] for the estimation of wave drag effects could thus only approximate high accuracy codes. Figure 6 indicates the results achieved with the empirical approaches above and the final values of compressibility drag counts used for the ACFA BWB design.

Further investigations on transonic aerodynamics being compatible with BWB applications are necessary if the subsequent design process is not to revert to $3 \mathrm{D}$ computational fluid dynamics (CFD) codes in the early phases of development.

\subsection{Control surface design}

Blended wing configurations feature an especially high coupling between flap deflections and aircraft movements in all three axes. As a result, multiobjective control surfaces are required for flight control and active gust and manoeuvre load alleviation. The main challenge is to provide sufficient yaw control and stability in the absence of a vertical tail if one engine is inoperative (OEI). This case is the dominant criterion for the pre-sizing of yaw control devices for the ACFA configuration with two top-rear high-bypass turbo fan engines and winglets.

For all configuration updates during the design loop, a flutter analysis has been performed as a basis for subsequent ACT investigations. Different flying velocities have been considered for weights ranging from maximum zero fuel weight to maximum takeoff weight (MTOW). Lumped masses were used for modelling payload, equipment, systems, and fuel. The integrated aerodynamic model has been developed with NASTRAN and the doublet lattice method has been used for considering the unsteady aerodynamics. A reference target envelope has been defined from the maximum operative speed (VMO) $(\mathrm{VMO}=340$ knots equivalent airspeed; KEAS). Design dive speed (VD) is 25 per cent higher than VMO and calculates to 425 KEAS [21]. Finally, the flutter reference limit value is 489 KEAS (1.15 VD) [22]. The modal analysis showed a high number of modes in a quite low frequency (up to $20 \mathrm{~Hz}$ ). Classical modes, such as wing bending and wing torsion, were well identified. A further structural upgrade of the model became necessary for a more realistic aircraft design. A parametric frequencies analysis has been performed with a progressive reduction of the winglet length, different positioning of the winglet, the addition of masses on the wing leading edge, and the increase of the outer wing skin thickness at project partners ALENIA and ONERA. In consequence, further structural models have been developed in order to remedy 


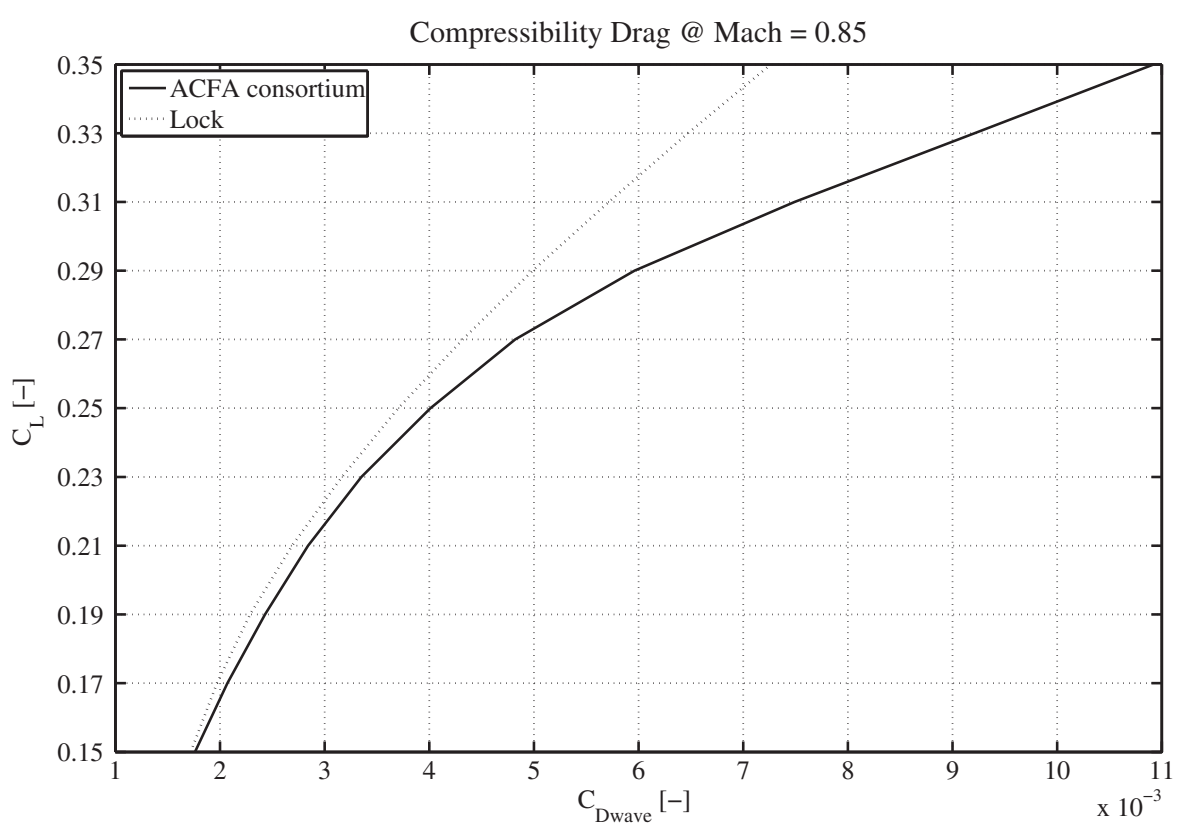

Fig. 6 Comparison of empirical transonic drag estimation methods

the critical aspects previously found. The final version of the model showed the desired separation between wing bending and wing torsion frequencies, which has a great importance for flutter aspects. The final winglet design led to the addition of $\pm 45^{\circ}$ ribs in the outer part of the wing, in order to increase the torsion stiffness of the wing. Furthermore, a winglet length reduction and an appropriate variation in the overall wing thickness have been applied. As the winglet height had to be reduced, the usage of winglets as the only source for yaw control became insufficient for handling the OEI case. To add the necessary yawing moment, crocodile flaps have been introduced in the very outer part of the wing. The preliminary sizing of the control surfaces presented in this study is subject to further possible modifications from subsequent investigations on active control of the aircraft: The detailed design of an all-composite, all-electric, and morphing trailing edge device and respective modelling and testing is described in Wildschek et al. [23]. The design of a prefilter for longitudinal motion control of a large flexible BWB aircraft is presented in Westermayer et al. [24]. The final control surface layout will be published in subsequent publications of the ACFA project.

\section{WEIGHT ESTIMATION}

Due to the fact that no full-scale BWB has yet been built, uncertainties remain in the design efforts. The problem of realistic weight estimation for flying wing configurations has been discussed by Bradley [25] and Howe [26] in their papers in 2004 and 2001, respectively. The stress level in BWB fuselages is an order of magnitude higher than for cylindrical pressurized fuselages because internal pressure primarily results in bending stress instead of skin-membrane stress [27]. Robust empirical methods have not been established yet. Hence, to keep the uncertainties as low as possible, high-fidelity finite element (FE) models have been designed from the early project phases onwards. Especially, the unconventional structural elements like the fuselage and the wingto-body fairing were parametrically build up to allow for design changes. Conventional structural elements like outer wing, systems, furnishings, and landing gear were calculated according to the federal aviation regulations (JAR) sections or derived from empirical databases of existing aircraft [28].

The BWB transports 34.8 tons of operator items and a payload of 49.5 tons. Fuel weight has been iteratively assessed with the Breguet/Leduc range equation. Table 1 shows the main weight parameters and a comparison with other recent BWB designs. The weight fraction operator empty weight (OEW)/ MTOW influences fuel burn. Most BWBs show higher values than comparable conventional aircraft mainly as a result from structural reinforcements due to non-tubular cross-sections. Regarding mission performance, this penalizing effect is offset by the higher aerodynamic efficiency of BWB configurations. However, discrepancies between BWB configurations regarding the ratio between payload and structural weight are evident. 


\section{PERFORMANCE}

\subsection{TO and landing}

Like conventional aircraft, BWBs have to meet FAR safety regulations and land on conventional airfields. Takeoff field length and landing field length as well as glide path angles influence the design of the high lift devices. In the absence of a tail to counteract pitching moments resulting from trailing edge control surface deflection, these surfaces cannot be used as conventional flaps. The moment required for rotation during TO is generated by upwardly deflected trailing edge flaps to counteract pitch (down) generated by engine thrust. At high angles of attack, flow separation further upstream can lead to low intake or heterogeneous pressures and thus decrease thrust output. This issue needs to be further examined in a detailed analysis of the TO performance. Trailing edge devices are sized by trim requirements rather than by high lift requirements [17]. This fact results in lower

Table 1 BWB configurations and respective weight parameters

\begin{tabular}{lllll}
\hline Configuration & $\begin{array}{l}\text { OEW } \\
(t)\end{array}$ & $\begin{array}{l}\text { Payload } \\
(t)\end{array}$ & $\begin{array}{l}\text { MTOW } \\
(t)\end{array}$ & $\begin{array}{l}\text { OEW/ } \\
\text { MTOW }\end{array}$ \\
\hline ACFA BWB & 225 & 50 & 401 & 0.56 \\
SAX40 BWB [5] & 208 & 52 & 333 & 0.62 \\
Boeing BWB-450 [17] & 187 & 89 & 373 & 0.50 \\
GbD BWB [29] & 207 & 86 & 430 & 0.48 \\
MOB BWB [4] & 137 & 113 & 371 & 0.37 \\
VELA 2 BWB [6] & 406 & 103 & 777 & 0.52 \\
NACRE FW-1 [3] & 357 & 71 & 700 & 0.51 \\
Boeing 747-400 [30] & 179 & 67 & 397 & 0.45 \\
\hline
\end{tabular}

maximum lift coefficients and lower wing loading. The maximum lift coefficient of a BWB aircraft is achieved at rather high angles of attack. As a result, the controllability of the BWB aircraft at low speeds is a crucial issue for the control surface design and the assessment of TO and landing speeds (Fig. 7). To determine these speeds, VMC (minimum control calibrated airspeed) has to be assessed. According to CS 25.149 (minimum control speed), it must be possible to prevent a heading change of more than $20^{\circ}$ at VMC at TO [31]. To cope with this requirement, several geometric alternatives of winglet rudder and split ailerons and their respective derivatives have been computed according to DATCOM to identify a VMC of 113 knots with a split ailerons inner limit at 75 per cent span. The solution was accepted because corresponding bank and sideslip angles are below the required limits $\left(\varphi=2.3^{\circ}\right.$ and $\left.\beta=10.1^{\circ}\right)$ and the BWB VMC is very similar to the VMC of a conventional aircraft. Furthermore, the BWB achieves the 2.4 per cent climb slope in a takeoff go around phase at 1.13 VS1g and the climb gradient achieved is 4.1 per cent with $45^{\circ}$ split ailerons deflection and $123 \mathrm{lbf}$ nominal engine thrust [32].

\subsection{Cruise analysis: Airframe/engine matching}

The detailed analysis of the mission performance enables the refinement and optimization of the overall aircraft design. A crucial step towards the latter is to match aerodynamic performance and engine size for maximum range cruise (MRC) with maximum fuel efficiency. Figure 8 depicts the results of the calculations and thus provides a graphical means to

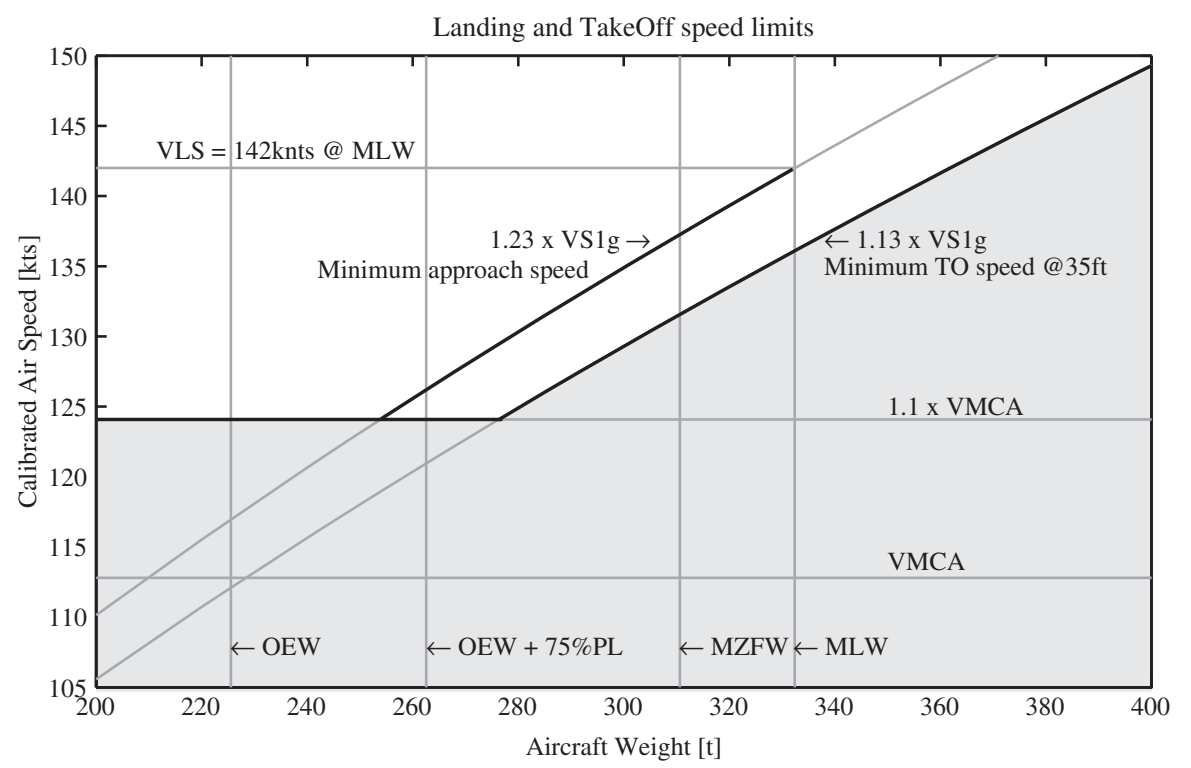

Fig. 7 BWB takeoff and landing speed determination chart 


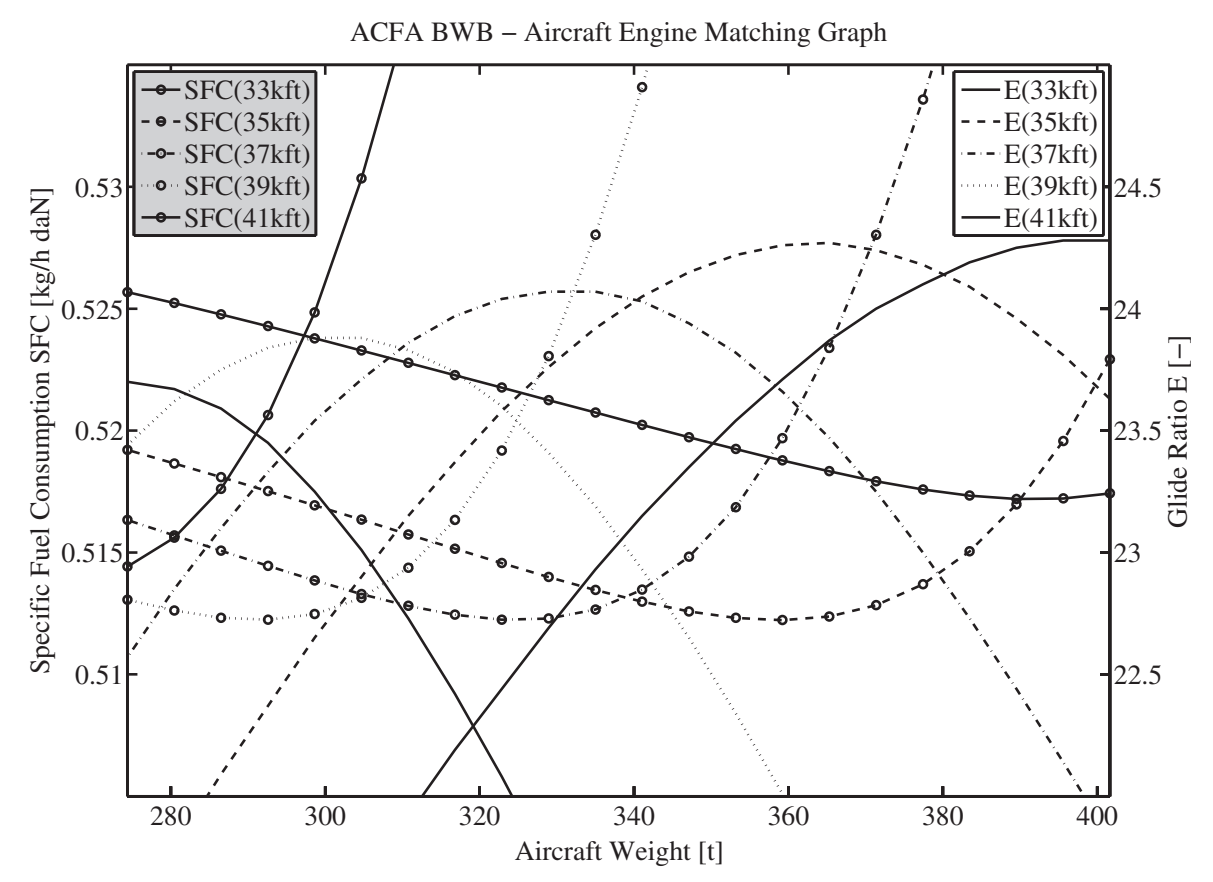

Fig. 8 Airframe/engine matching graph

determine how the current engine design fits the airframe aerodynamics. If maximum glide ratio and minimum specific fuel consumption match at a certain altitude, MRC is achieved. The vertical flight profile can be derived from the underlying data set and be used as input for the mission analysis and the design goal: minimization of fuel burn on the $7200 \mathrm{~nm}$ mission.

\section{CONCLUSIONS AND PERSPECTIVE}

\subsection{Conclusions}

In this article, the key results from the incorporated ACT aircraft design process are presented. Especially, the inherent problems of BWB designs like profile selection, stability margin, and TO performance have been discussed. Due to the unconventional aircraft structural layout, high-fidelity FE models were used from the early phases. The investigation of compressible aerodynamics, i.e. changing positions of the aerodynamic centre or TO considerations revealed the need for robust methods in the available tool chain. It can be recommended that for future investigations high-fidelity CFD codes may be used from early project phases onwards. However, the proposed design process proved its efficiency during a resizing effort of the winglet. The overall aircraft design finally met all the stated requirements and it presents the baseline configuration for ACT investigation within the ACFA consortium.

\subsection{Contribution to ACARE vision}

The implementation of new aircraft configurations like blended wings is associated with high technological and economical risks. As a result, the benefits of blended wing configurations have to be significant to be pursued; 50 per cent fuel reduction and related $\mathrm{CO}_{2}$ emissions per passenger-kilometre are stated as goals in the ACARE vision 2020. To find a reference aircraft for a meaningful comparison with regard to 'fuel reduction' is rather intricate. As every aircraft has its own design point, it is not adequate to compare two different aircraft on one mission (payload/ range combination). The results will vary if the design point of one aircraft or the other is considered. However, several comparisons of fuel efficiency (fuel burn per PAX per nautical mile) between BWB-type aircraft and comparable conventional configurations can be found in literature [29, 17]. These comparisons have been calculated at the respective design point of the BWB aircraft and engine technology levels of the respective entry-into-service date are assumed (Table 2)

The SRA goal of reducing $\mathrm{CO}_{2}$ emissions by 50 per cent per passenger-kilometre assumes that new airframes can contribute 20-25 per cent, new engine technologies 15-20 per cent, and air traffic management 5-10 per cent [2]. The comparison above shows that the higher aerodynamic efficiency of the BWB aircraft significantly contributes to reduced $\mathrm{CO}_{2}$ emissions and thus lies within the SRA goals. To substantiate the beneficial effects of blended wings, the 
Table 2 Comparison between BWB and conventional aircraft configurations

\begin{tabular}{|c|c|c|c|}
\hline Configuration comparison & Payload (kg) & Range (nm) & $\Delta$ Block fuel \\
\hline ACFA BWB/B747-400 & 49350 & 7200 & $24 \%$ Less for BWB \\
\hline GdB BWB/Conventional AC [29] & 86000 & 6750 & $23 \%$ Less for BWB \\
\hline BWB-450/Airbus A380-700 [17] & 45720 & 8700 & $32 \%$ Less for BWB \\
\hline
\end{tabular}

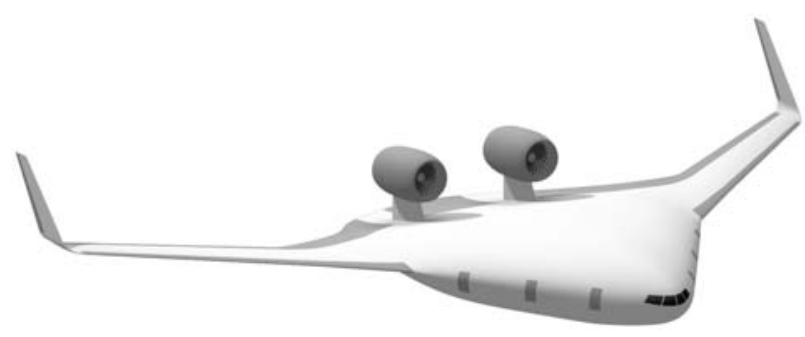

Fig. 9 Rendering of the ACFA BWB configuration

BWB should be analysed in detail within the current air traffic network.

\subsection{Contribution to the ACFA 2020 project}

Thisarticle describes the sizing process of the preliminary BWB aircraft configuration which represents the basis of succeeding ACFA investigations. The possibility of resizing the aircraft structure with active control mechanisms has not been carried out so far. The potential weight benefits resulting from active control on blended wings are to be released in successive publications. The current configuration, however, enabled the investigation of ACT principles and a framework of a new design process was successfully established. The efficiency of the proposed aircraft design framework was proven during a highly interactive effort to resize the winglet and respective control surfaces. Although minor design issues remain unsolved, the current configuration seems highly attractive for further studies as a very promising overall aircraft concept (Fig. 9).

\section{ACKNOWLEDGEMENTS}

The authors thank all ACFA 2020 partners for their contributions. Moreover, the authors are grateful to R. Maier and A. Wildscheck from EADS-IW as well as J.-J. Mirat and T. Salmon from Airbus France for their continuous support. The authors also thank all the participating colleagues from Technische Universität München, namely K. Ploetner, C. Roessler, and B. Brueckner, as well as F. Stroscher and Ö. Petersson.

\section{FUNDING}

This study was supported by European Commission within the seventh Research Framework Programme [grant agreement no. ACP7-GA-2008-213321].

(C) TUM - Prof. Mirko Hornung 2011

\section{REFERENCES}

1 Office for Official Publications of the European Communities. European aeronautics: a vision for 2020, meeting society's needs and winning global leadership, Luxembourg, 2001.

2 ACARE - Advisory Council for Aeronautics Research in Europe. 2008 addendum to the strategic research agenda, Belgium, ACARE, Brussels, 2008.

3 Gall, P. E. New Aircraft Concepts Research (NACRE). Aeronautics Days, Airbus S.A.S. Vienna, Austria, 19-21 June 2006.

4 Morris, A., Arendsen, P., LaRocca, G., Laban, M., Voss, R., and Hönlinger, H. MOB - a European project on multidisciplinary design optimization. In Proceedings of the 24th international congress of the aeronautical sciences, Yokohama, Japan, 29 August-3 September 2004.

5 Hileman, J. I., Spakovszky, S. Z., and Drela, M. Airframe design for "silent aircraft". In Proceedings of the 45th AIAA aerospace sciences meeting and exhibit, Reno, Nevada, United States of America, 8-11 January 2007, paper no. AIAA 2007-0453 (American Institute of Aeronautics and Astronautics, Reston, Virginia).

6 Kresse, N. VELA- Very Efficient Large Aircraft, A FP5 project to enhance the knowledge on BWB configurations. Aeronautics Days, Vienna, Austria, 19-21 June 2006.

7 Ricouard, J., Davy, R., Loheac, P., Moore, A., and Piccin, 0. ROSAS wind tunnel test campaign dedicated to unconventional aircraft concepts study. In Proceedings of the 10th AIAA/CEAS Aeroacoustics Conference, Manchester, UK, 10-12 May 2004, paper no. AIAA-2004-2867 (American Institute of Aeronautics and Astronautics, Reston, Virginia).

8 König, J. The European R\&T platform AWIATOR: bringing new aircraft technologies into the air. Aeronautics Days, Vienna, Austria, 19-21 June 2006.

9 Kordt, M. MODYAS - Multi Objective Dynamic Aircraft Synthesis, Airbus Operations $\mathrm{GmbH}$, Germany, Hamburg, 2008. 
10 Weise, K. Anwendung von Active Control bei Verkehrsflugzeugen, MBB GmbH, Germany, Hamburg, 1980.

11 Moorhouse, D. J. Flight control design best practices relative to active control technology. In Proceedings of the RTO AVT Symposium on Active control technology for enhanced performance operational capabilities of military aircraft, land vehicles and sea vehicles, Braunschweig, Germany, 8-11 May 2000, pp. 25-1-25-8.

12 XFLR5, Analysis tool for airfoils, wings and planes operating at low Reynolds numbers, Software Package, ver. 6.02, Available from http://xflr5.sourceforge.net/xflr5.htm (accessed 5 January 2010).

13 Qin, N., Vavalle, A., and Moigne, A. L. Spanwise lift distribution for blended wing body aircraft. J. Aircr., 2005, 42(2), 356-365.

14 Williams, J. E. and Vukelich, S. R. The USAF stability and control digital dATCOM. Volume I. Users manual, AFFDL-TR-79-3032, Air Force Flight Dynamics Laboratory, vol. 1, 1979.

15 Schemensky, R. T. Development of an empirically based computer program to predict the aerodynamic characteristics of aircraft, AFFDL-TR-73-144, Air Force Flight Dynamics Laboratory, 1973.

16 Torenbeek, E. Synthesis of subsonic airplane design: an introduction to the preliminary design of subsonic general aviation and transport aircraft, with emphasis on layout, aerodynamic design, propulsion and performance, 1982 (Springer, AZ Dordrecht, The Netherlands).

17 Liebeck, R. H. Design of the blended wing body subsonic transport. J. Aircr., 2004, 41 (1), 10-25.

18 Diedrich, A., Hileman, J., Tan, D. Willcox, K., and Spakovszky, Z. Multidisciplinary design and optimization of the silent aircraft. In Proceedings of the 44th AIAA aerospace sciences meeting and exhibit, Reno, Nevada, United States of America, 9-12 January 2006, paper no. AIAA 2006-1323 (American Institute of Aeronautics and Astronautics, Reston, Virginia).

19 Leifsson, L., Mason, W., Schetz, J., Grossman, B., and Haftka, R. Multidisciplinary design optimization of low-airframe-noise transport aircraft. In Proceedings of the 44th AIAA aerospace sciences meeting and exhibit, Reno, Nevada, USA, 9-12 January 2006, paper no. AIAA 2006-230 (American Institute of Aeronautics and Astronautics, Reston, Virginia).

20 Malone, B. and Mason, W. H. Multidisciplinary optimization in aircraft design using analytic technology models. J. Aircr., 1995, 32(2), 431-438.

21 European Aviation Safety Agency (EASA). CS-25.335 design airspeeds (b), European Aviation Safety Agency, Belgium, Brussels, 2003.

22 European Aviation Safety Agency (EASA). CS/AMC25.307 proof of structure, European Aviation Safety Agency, Belgium, Brussels, 2003.

23 Wildschek, A., Havar, T., and Plötner, K. An allcomposite, all-electric, morphing trailing edge device for flight control on a blended-wing-body airliner. J. Aerosp. Eng., 2010, 224(1), 1-9.

24 Westermayer, C., Schirrer, A., Hemedi, M., and Kozek, M. An $\mathrm{H} \infty$ full information approach for the feedforward controller design of a large BWB flexible aircraft. In Proceedings of the 4th European Conference for Aerospace sciences (EUCASS), paper no. 658. Saint Petersburg, Russia, 4-8 July 2011.

25 Bradley, K. A sizing methodology for the conceptual design of blended-wing-body transports, NASA/CR2004-213016, The National Aeronautics and Space Administration, Washington, D.C., 2004.

26 Howe, D. Blended wing body airframe mass prediction. Proc. IMechE, Part G: J. Aerospace Engineering, 2001, 215(6), 319-331.

27 Mukhopadhyay, V. Blended-Wing-Body (BWB) fuselage structural design for weight reduction. In Proceedings of the 46th AIAA/ASME/ASCE/AHS/ASC structures, structural dynamics and materials conference, Austin, Texas, 18-21 April 2005, paper no. AIAA 2005-2349 (American Institute of Aeronautics and Astronautics, Reston, Virginia).

28 Luftfahrttechnisches Handbuch, Massenanalyse (weight calculation), IAB $\mathrm{G} \mathrm{mbH}$, Ottobrunn, Germany, 2008.

29 Intergovernmental Panel on Climate Change. Climate change 2007 -mitigation of climate change, Contribution of working group III to the fourth assessment report of the Intergovernmental Panel on Climate Change, Cambridge University Press, New York: USA, 2007.

30 Boeing Commercial Airplanes. 747-400 airplane characteristics for airport planning, The Boeing Company, Seattle, Washington, USA, 2002.

31 European Aviation Safety Agency (EASA). CS/AMC25.149 minimum control speed, European Aviation Safety Agency, Brussels, Belgium, 2003.

32 Salmon, T. Comparison dossier of the two 450 passenger aircraft configurations for ACFA2020, Internal Deliverable, France, Chatillon, 2009.

\section{APPENDIX}

\section{Notation}

$C_{\mathrm{L}} \quad$ lift coefficient

$C_{\mathrm{m}} \quad$ pitching moment coefficient

$C_{\mathrm{p}} \quad$ pressure coefficient

$D \quad$ drag

E glide ratio; lift/drag ratio

FP7 Framework Programme Seven

$L \quad$ lift

MLW maximum landing weight

OEW operator empty weight

VLS lowest selectable approach speed

VMC minimum control calibrated airspeed

VS stall speed 